\title{
Uptake and Toxicity Studies of Poly-Acrylic Acid Functionalized Silicon Nanoparticles in Cultured Mammalian Cells
}

\author{
Qi Wang, Yongping Bao, Xiaohong Zhang, Paul R. Coxon, Upali A. Jayasooriya, \\ and Yimin Chao*
}

Poly-acrylic acid (PAAc) terminated silicon nanoparticles (SiNPs) have been synthesized and employed as a synchronous fluorescent signal indicator in a series of cultured mammalian cells: HHL5, HepG2 and 3T3-L1. Their biological effects on cell growth and proliferation in both human and mouse cell lines have been studied. There was no evidence of in vitro cytotoxity in the cells exposed to PAAc terminated SiNPS when assessed by cell morphology, cell proliferation and viability, and DNA damage assays. The uptake of the nanocrystals by both HepG2 and 3T3-L1 cells was investigated by confocal microscopy and flow cytometry, which showed a clear time-dependence at higher concentrations. Reconstructed 3-D confocal microscope images exhibited that the PAAc-SiNPs were evenly distributed throughout the cytosol rather than attached to outer membrane. This study provides fundamental evidence for the safe application and further modification of silicon nanoparticles, which could broaden their application as cell markers in living systems and in micelle encapsulated drug delivery systems.

\section{Introduction}

The study of nanoparticles (NPs) has significantly increased in the past decade and has attracted interest from a wide field across the scientific community. ${ }^{[1-6]}$ Owing to the flexibility of manufacturing methods which can yield NPs of different sizes, shapes and surface modifications, specially engineered NPs

Q. Wang, Dr. P. R. Coxon,

Dr. U. A. Jayasooriya, Dr. Y. Chao

Energy Materials Laboratory

School of Chemistry

University of East Anglia, Norwich, NR4 7TJ, UK

E-mail:y.chao@uea.ac.uk

Dr. Y. Bao

Norwich Medical School

University of East Anglia

Norwich, NR4 7TJ, UK

Prof. X. Zhang

School of Medicine

Ningbo University

Zhejiang, 315211, P. R. China

DOI: 10.1002/adhm.201100010 can be used in a variety of applications; not least in biological imaging ${ }^{[3,7-9]}$ where information on cellular components and processes is typically visualised by fluorescence microscopic imaging. This is done by attaching fluorophores to molecules which bind to the desired targets via molecular recognition pathways and allow the system of interest to be imaged. ${ }^{[10,11]}$ Traditionally organic dyes and fluorescent proteins serve as the fluorophore in most biological systems as they are highly water soluble and bioconjugate with the intended target easily. ${ }^{[10]}$ However, the rapid development of biomedical sciences now demands new advanced techniques and instruments. ${ }^{[10,11]}$ Semiconductor nanoparticles have several advantages over and above dye and protein-based labels making them ideal candidates to replace current imagine techniques in many biological assays and fluorescence imaging routines, ${ }^{[7]}$ such as tunable fluorescence signatures, ${ }^{[12-14]}$ high quantum efficiency ${ }^{[15]}$ and stability against photobleaching. ${ }^{[16,17]}$ As the range and extent of nanoparticle applications has risen over time, the security and biological effects of nanomaterials within organic media have emerged as a new focus of research. Small nanoparticles (with diameters of $<10 \mathrm{~nm}$ ) can act as effective drug carriers in cancer therapies since they can more readily diffuse throughout the tumor tissue's interstitial space. ${ }^{[1]}$ These require a thorough understanding of the mechanisms involved in the cellular uptake, and the intracellular localization for the various types of nanoparticles used. ${ }^{[18,19]}$ In addition, it is essential that NPs are water soluble and hydrophilic to prevent aggregation and precipitation in the biological environment. The most widely used and best understood nanoparticle fluorophores are based on $\mathrm{CdS}$, CdSe, CdTe, or ZnS..$^{[8,10,11]}$ However, in vitro studies suggest that under certain conditions these classes of nanoparticles may be cytotoxic. ${ }^{[20]}$ The cytotoxicity is mainly attributed to the leaching of heavy metal ions such as $\mathrm{Cd}^{2+}$, although some reports indicate the formation of free radicals which lead to cell death. ${ }^{[21,22]}$ Owing to their low inherent toxicity, ${ }^{[23]}$ silicon nanoparticles (SiNPs) have the potential to overcome the inherent limitation of heavy metal nanoparticles in biomedical applications. As a result, research on the biological effects of SiNPs 
has grown in importance and gained extensive attention. To address these problems we have synthesized poly-acrylic acid terminated silicon nanoparticles (PAAc-SiNPs) that are chemically stable and exhibit strong red luminescence. ${ }^{[2,25]}$ The biocompatibility of PAAc-SiNPs and cytotoxicity are important parameters to evaluate whether these SiNPs can be used safely in biomedical environments. In order to establish if the PAAcSiNPs can be employed to study intracellular functions without disrupting cellular activity, we have carried out in vitro cellular studies using a variety of cell lines. The study was designed to determine the potential cytotoxicity and cellular uptake efficiency against incubation time and SiNP concentration. These intensely fluorescent PAAc-SiNPs were found to accumulate in the cytosols and showed no significant cytotoxicity.

\section{Results}

\subsection{Physical Characteristics of PAAc-SiNPs}

The SiNPs studied in this work are composed of a crystalline silicon core capped with a poly-acrylic acid layer. Hydrogenterminated silicon surfaces were produced by galvanostatic anodization in a 1:1 HF:ethanol solution. The Si-H surface bond can then be treated with poly-acrylic acid to form hydrophilic silicon nanoparticles (Figure 1a). The SiNPs display intense

(a)
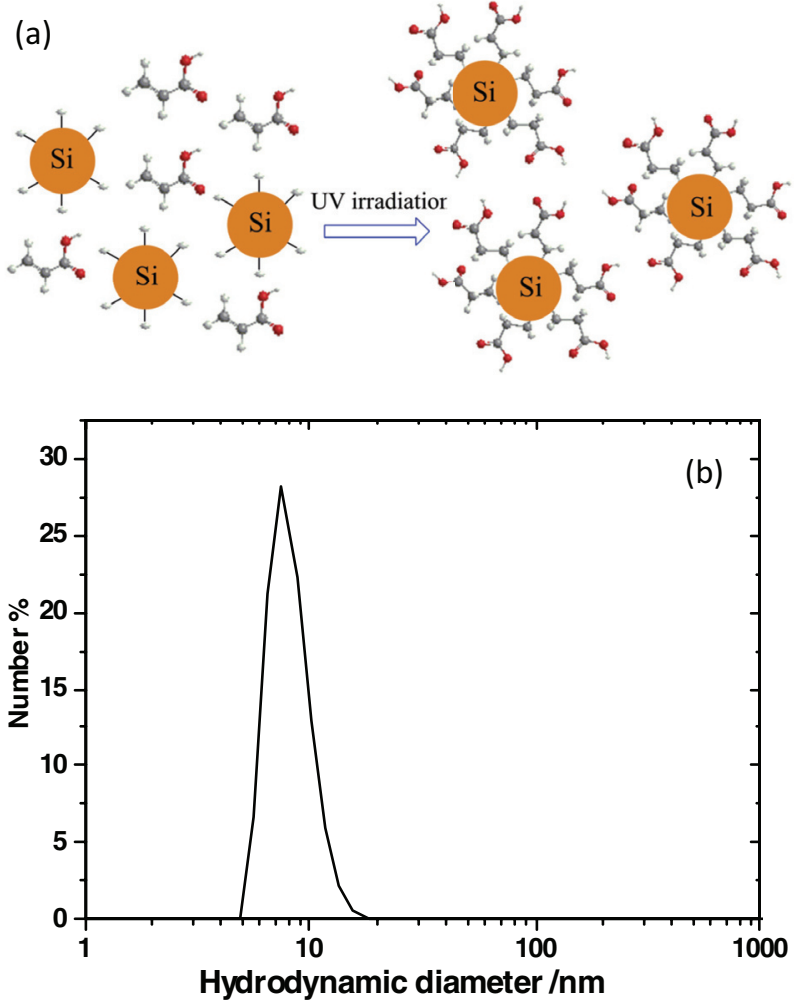

Figure 1. (a) Schematic representation of the hydrosilylation of silicon nanoparticles in acrylic acid. Surface Si atoms of the nanoparticles change from $\mathrm{H}$ - to PAAc termination under UV illumination; (b) DLS distribution curves of silicon nanoparticles suspended in PBS $(10.5 \pm 3.0 \mathrm{~nm})$, $0.2 \mu \mathrm{nm}$ pore size filtration was applied before the measurement. luminescence under excitation with $\lambda_{\mathrm{ex}}=310 \mathrm{~nm}$ light. The emission spectrum is centred at $600 \mathrm{~nm}$ and is independent of the excitation wavelength. ${ }^{[25]}$ The SiNPs are hydrophilic and therefore have relatively high miscibility in polar solvents. The SiNPs were found to be readily suspended in a range of solvents including water, ethanol and phosphate-buffered saline (PBS).

Dynamic light scattering (DLS) measurements revealed the main diameter of these particles in PBS to be $10.5 \pm 3.0 \mathrm{~nm}$ (Figure 1b), which is larger than AFM results reported on the samples previously, ${ }^{[25]}$ and HRTEM results (see supporting information). This is because DLS is measuring the hydrodynamic diameter of the particle, thus effectively measuring the nanoparticle and anything affiliated with its surface which could be a surrounding double-layer, capping agents, or nanoparticle aggregates. The DLS measurements also confirm that the hydrodynamic diameter of the particles remains practically unchanged after dispersion in water for at least 4 days (see supporting information). The stability of the poly-acrylic acid capped SiNPs has been monitored over periods of several months which showed that the samples remain very stable if they are stored in a dark and radiation free environment, which is in line with the results from other group. ${ }^{[26,27]}$ The photoluminescence in PBS obtained over 4 weeks is shown in supporting information.

Chemical bonding of SiNPs with poly-acrylic acid ligands was investigated by high-resolution X-ray photoelectron spectroscopy (XPS) over the $\mathrm{Si} 2 p, \mathrm{C} 1 s$ and O1s regions of the SiNPs (Figure 2 and Figure S3). The Si2p spectrum (Figure 2) was fitted with three mixed Gaussian-Lorentzian doublets against a Shirley background profile. The first component at $100 \mathrm{eV}$ is assigned to $\mathrm{Si}-\mathrm{Si}$ bonding within the silicon core of the SiNPs. The second at $102 \mathrm{eV}$ is from $\mathrm{Si}-\mathrm{C}$ and the third at $104 \mathrm{eV}$ from $\mathrm{SiO}_{2}$ at the surface of SiNPs, respectively. ${ }^{[28]}$ XPS spectra over the $\mathrm{C} 1 s$ and $\mathrm{O} 1 s$ regions can be found in supporting information. By the presence of a $\mathrm{Si}-\mathrm{C}$ component in the $\mathrm{Si} 2 p$ region

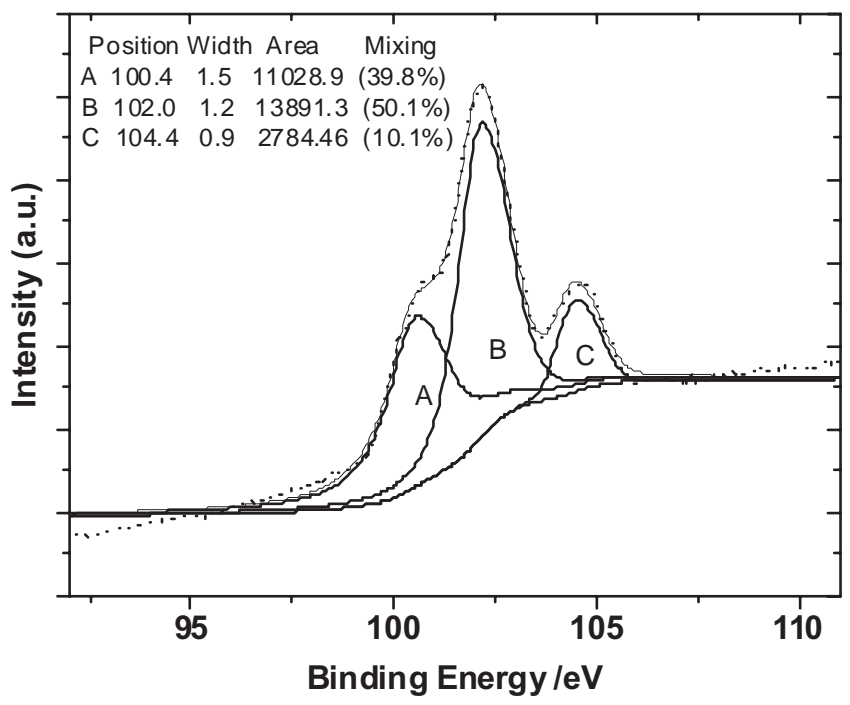

Figure 2. XPS core-level spectrum the Si2p regionof Si-NPs obtained at normal emission with a photon energy $1486.7 \mathrm{eV}$ : the dotted lines are experimental data that were fitted by peaks with a mixed linear combination of Gaussian-Lorentzian function profiles. 
we can deduce the surface silicon atoms of the NPs have undergone $\mathrm{H}$ - to poly-acrylic acid termination. ${ }^{[12]}$ Clearly the peak at $104 \mathrm{eV}$ suggests the presence of surface oxide and from the relative area each peak component contributes to the overall fitted spectrum (indicated within the figure) we can determine, to a first approximation, the degree of PAAc coverage within the samples. By the fit performed we estimate $83 \%$ of the silicon surface is bound by $\mathrm{Si}-\mathrm{C}$ bonds to the PAAc capping layer while the remaining $17 \%$ is surface oxide. This compares favourably with SiNPs surfaces bound by organic monolayers chains where $50 \%$ surface coverage is typical. ${ }^{29,30]}$ The degree of oxidation listed here is a qualitative estimation based upon the structure and chemical makeup of the nanoparticles studied in the work presented here. While it is true that the degree of surface oxidation of silicon nanostructures will play a role in the electronic density of states and consequently the photoluminescence profile, ${ }^{[31,32]}$ such studies are not presented here and are thus a course for future research upon PAAc capped SiNPs.

\subsection{In vitro Cytotoxicity Assays}

Different type of nanoparticles possesses their own particular physicochemical properties, which in turn determines their potential toxicity or lack thereof. The effect of PAAc-SiNPs on the proliferation and viability of cells was determined by MTT assay and trypan blue stain respectively. HHL-5 (immortalised human hepatocytes), HepG2 (human liver hepatocellular carcinoma), 3T3-L1 (mouse embryonic fibroblast - adipose like cell line) cells were plated in $200 \mu \mathrm{l}$ of complete culture medium containing $0.1-200 \mu \mathrm{g} \cdot \mathrm{mL}^{-1}$ concentrations of PAAc-SiNPs in 96-well plates for 24 and 48 hours. There was no evidence of morphology change when the cells were observed under a phase-contrast microscope. The values of cytotoxicity induced by PAAc-SiNPs are given in Figure 3. As shown in Figure 3a, treatment with poly-acrylic acid functionalized nanoparticles $\left(0-200 \mu \mathrm{g} \cdot \mathrm{mL}^{-1}\right)$ did not markedly effect the proliferation of HepG2cells. PAAc-SiNP treatment $\left(0-200 \mu \mathrm{g} \cdot \mathrm{mL}^{-1}\right)$ did not result in a dose-dependent inhibition of cell growth, when compared to vehicle-treated controls. PAAc-SiNP treatment also resulted in no time dependent inhibition of the cells' growth. As shown in Figure 3b, the trypan blue cell viability assay also suggested lack of cytotoxic effects of PAAc-SiNPs upon the cells, which is consistent with the pattern in the MTT assay (Figure 3a).

Furthermore, the results from the MTT assay (Figure 3c) suggest the PAAc-SiNPs did not cause any apparent harm to the proliferation of the different types of cells (both human and mouse cells lines). There were no significant differences $(p>0.05)$ in the cell proliferation and viability between PAAcSiNP treated and control cells.

To assess the effects of PAAc-SiNP on DNA damage, PAAcSiNP treated HepG2 and HHL-5 cells were analyzed by alkaline comet assays to monitor total DNA strand breaks. ${ }^{[33]}$ Figure 4 shows the results on HepG2 cells. Exposing cells to $50 \mu \mathrm{M} \mathrm{H}_{2} \mathrm{O}_{2}$ (positive control) followed by a 1 hour incubation period, resulted in a high level of DNA damage, visualised as comets, see Figure 4b, such that about half DNA was in the tail. However, in PAAc-SiNP treated cells, no significant comet
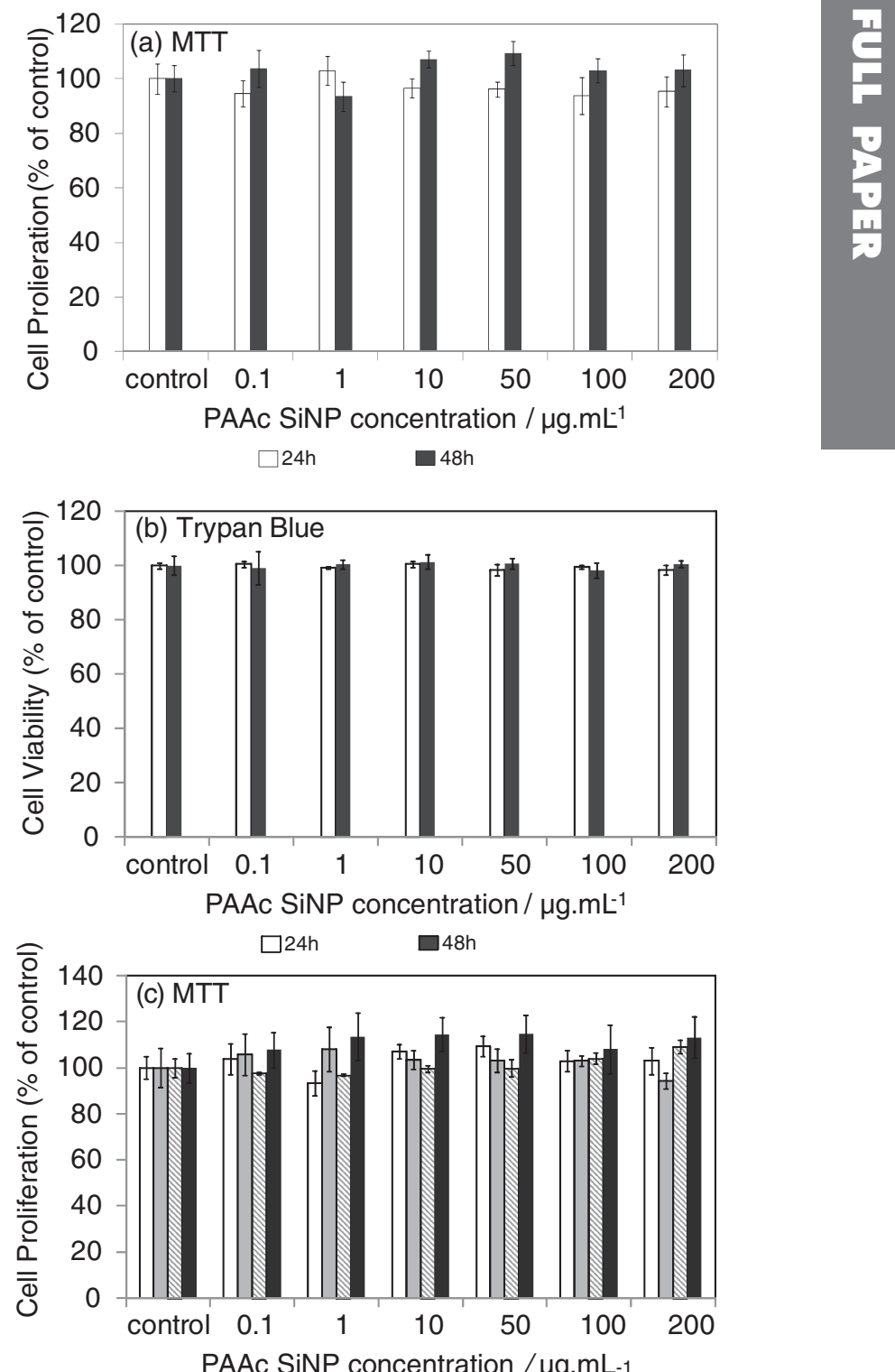

$\square$ HepG2 $\square$ HHL5 $\square$ 3T3-L1 pre-adipocyte $\square$ 3T3-L1 mature adipocyte

Figure 3. Effect of PAAc-SiNPs on cell proliferation and viability. HepG2 cells were treated with PAAc-SiNPs $\left(0.1-200 \mu \mathrm{g} \cdot \mathrm{mL}^{-1}\right)$ for 24 hours (white columns) and 48 hours (dark columns) and the proliferation of cells was determined by MTT assay (a) and viability of cells was measured by typan blue staining (b). There was no evidence of acute cytotoxicity, as evident from trypan blue assay performed on HepG2. (c) HepG2 (white column), HHL5 (light gray column), 3T3-L1 pre-adipocyte (gray wide downward diagonal column), and 3T3-L1 mature adipocyte (dark column) cells were exposed to indicated concentration of SiNPs for 48 hours. Cell proliferation was determined by MTT assay. The data are expressed as the percentage of cell viability compared with the untreated control and represent the mean $\pm S D$ of three independent experiments.

tail formation was be observed, indicating no significant DNA strand breakage, see Figure $4 \mathrm{c}$ and Figure $4 \mathrm{~d}$. This result suggests our nanoparticles do not induce oxidative DNA damage in the cells, which combined with MTT cell viability results, if 

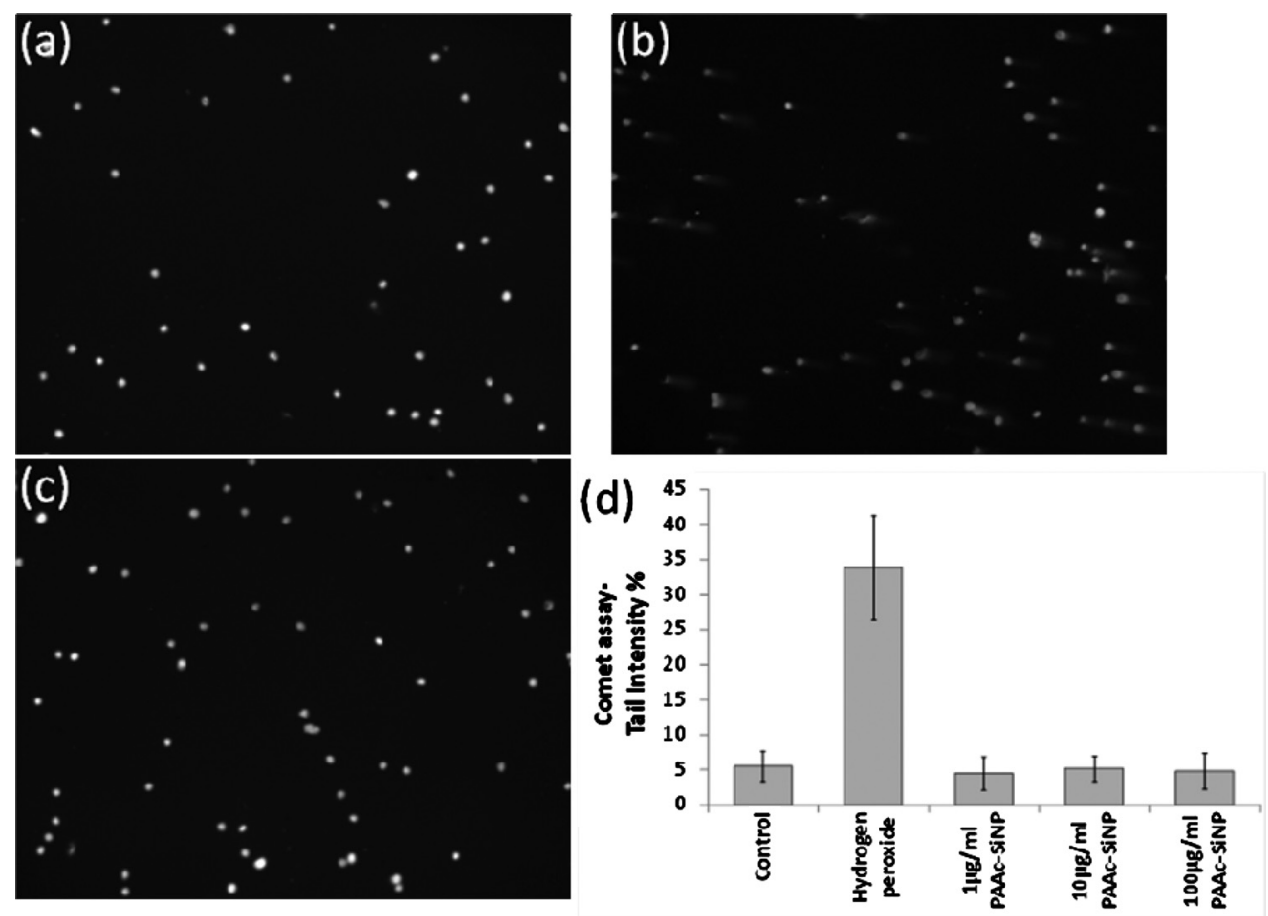

Figure 4. PAAc-SiNP effect on DNA damage in $\mathrm{HepG} 2$ cells were analyzed with the comet assay: (a) negative control, cell incubated with medium only; (b) positive control, cells were exposed to $50 \mu \mathrm{M} \mathrm{H}_{2} \mathrm{O}_{2}$ for $1 \mathrm{~h}$; (c) cells were treated with $100 \mu \mathrm{g} \cdot \mathrm{mL}^{-1}$ PAAcSiNPs for 1 hour; (d) PAAc-SiNP dose effect of the extent of DNA damage. Damage is expressed in tail moment analyzed by Comet IV software. The values are the mean \pm S.E. of 60 cells.

follows the PAAc-SiNPs have no cytotoxic effects on the cells, ands may be deemed safe to use as a potential fluorescent probe in bioimaging assays. Comet assay results on HHL-5 cells can be found in supporting information Figure S4.

\subsection{Uptake of PAAc-SiNPs in Cultured Mammalian Cells}

Cultured cells can take up nanoparticles when they were incubated together, but the ability to become internalized within cells is different for different types of nanoparticles. Confocal microscopy and flow cytometry were used to study the uptake of PAAc-SiNPs in the various cell lines. Figure 5 shows a confocal image of HepG2 incubated with 50 or $100 \mu \mathrm{g} \cdot \mathrm{mL}^{-1}$ SiNPs for different incubation times. After being incubated for 1 hour, it was found that PAAc-SiNPs began to accumulate in the cell at the concentration of $100 \mu \mathrm{g} \cdot \mathrm{mL}^{-1}$ (Figure $5 \mathrm{~b} 2$ ). However, the uptake of PAAc-SiNPs at $50 \mu \mathrm{g} \cdot \mathrm{mL}^{-1}$ concentrations was much slower. The fluorescent signals of PAAc-SiNPs in the HepG2 cells could be clearly observed after they had been incubated for 4 hours (Figure $5 \mathrm{~d} 1$ ) with $50 \mu \mathrm{g} \cdot \mathrm{mL}^{-1}$ PAAc-SiNPs, but only after 2 hours (Figure $5 \mathrm{c} 2$ ) for a concentration of $100 \mu \mathrm{g} \cdot \mathrm{mL}^{-1}$. After incubation for 12 hours, there was no significant difference between the fluorescent signals of both concentrations, which suggests the uptake was almost saturated (Figure 5f).

Confocal images on 3T3-L1 cells can be found in Figure S5 within the supporting information. A similar behaviour was observed by confocal microscopy. In order to observe a clear fluorescent signal a longer incubation time was needed with low concentration of PAAc-SiNPs than with high concentration. And after 24 hours incubation, the fluorescent signal was saturated. From which we may conclude that uptake of PAAc-SiNPs in HepG2 cells is faster than in 3T3-L1 cells.

To examine the spread of SiNPs within HepG2 cells, z-stack images collected at $0.37 \mu \mathrm{m}$ intervals. Figure 6 displays the accumulation of particles within the cells with the PAAc-SiNPs appearing evenly distributed throughout the cytosol rather than attached to outer membrane only.

Figure 7 and 8 show the uptake efficiency of SiNPs in HepG2 cells. The rightward shift in the curve represents an increase in fluorescent signal. This result indicatesthat the fluorescent signals of PAAc-SiNPs in HepG2 cells can only be detected when exposed to a relatively high level concentration of particles. A statistically significant increase of the relative fluorescence intensity occurred when the SiNPs concentration was greater than $100 \mu \mathrm{g} \cdot \mathrm{mL}^{-1}$ (Figure 8c). Treatment with SiNPs at $100 \mu \mathrm{g} \cdot \mathrm{mL}^{-1}$ resulted in a trend towards a time-dependent increase in fluorescence intensity (Figure 7c). The fluorescent signal increased gradually with incubation time, indicating that PAAc-SiNPs accumulated within the cells during incubations up to 72 hours.

\section{Discussion}

A large number of studies on the cytotoxic effects of carbon-, metal-, and group II-VI semiconductor-based nanoparticles have been reported recently, ${ }^{[20]}$ however, few were on silicon 

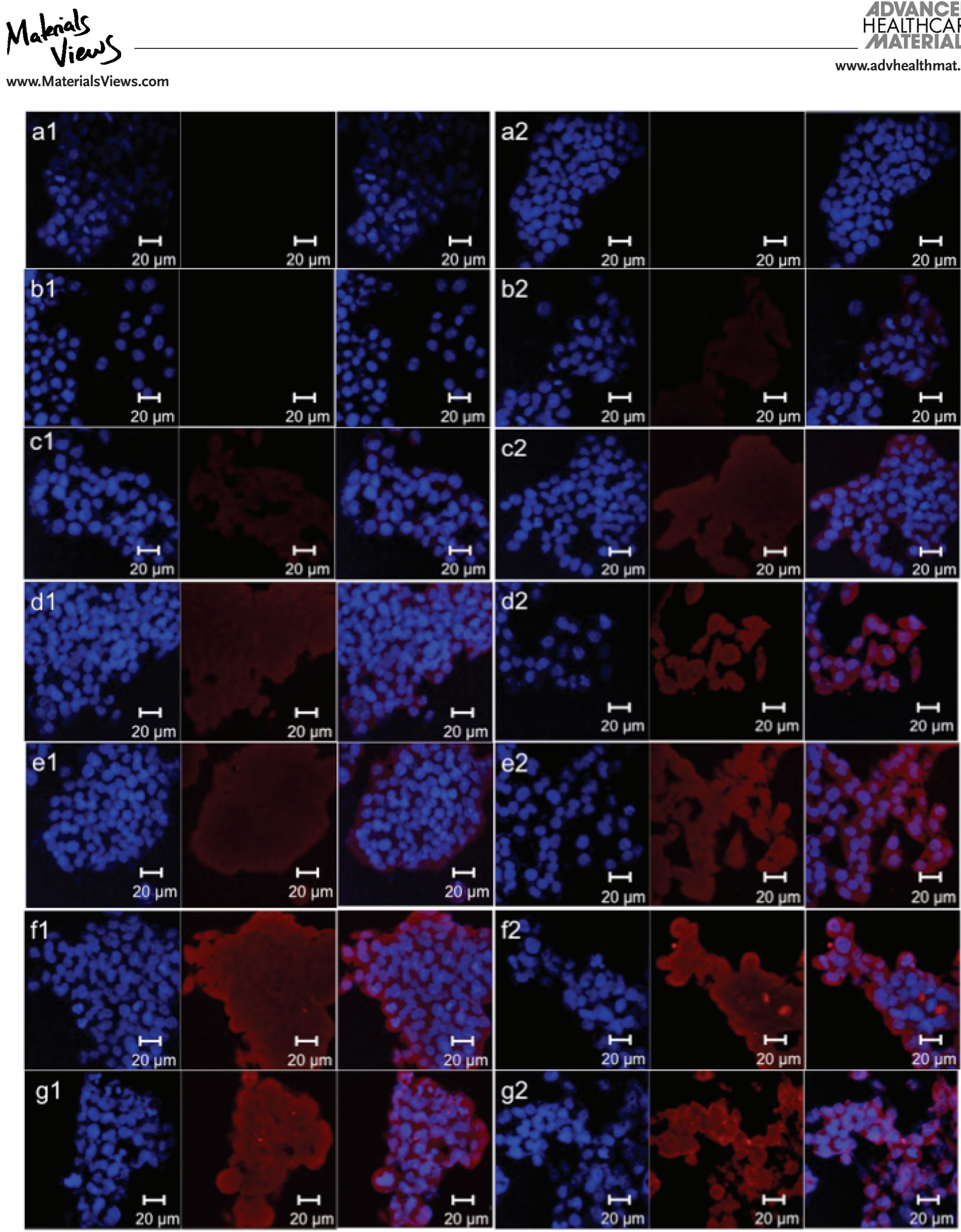

Figure 5. Confocal image of HepG2 cells incubated with a1\&2) 1 hour and 24 hour incubation with medium only, b1) $50 \mu \mathrm{g} \cdot \mathrm{mL}^{-1} \mathrm{PAAc}-\mathrm{SiNPs}$ for 1 hour, b2) $100 \mu \mathrm{g} \cdot \mathrm{mL}^{-1}$ PAAc-SiNPs for 1 hour, c1) $50 \mu \mathrm{g} \cdot \mathrm{mL}^{-1}$ PAAc-SiNPs for 2 hours, c2) $100 \mu \mathrm{g} \cdot \mathrm{mL}^{-1}$ PAAc-SiNPs for 2 hours, d1) $50 \mu \mathrm{g} \cdot \mathrm{mL}^{-1}$ PAAc-SiNPs for 4 hours, d2) $100 \mu \mathrm{g} \cdot \mathrm{mL}^{-1}$ PAAc-SiNPs for 4 hours, e1) $50 \mu \mathrm{g} \cdot \mathrm{mL}^{-1}$ PAAc-SiNPs for 8 hours, e2) $100 \mu \mathrm{g} \cdot \mathrm{mL}^{-1}$ PAAc-SiNPs for 8 hours, f1) $50 \mu \mathrm{g} \cdot \mathrm{mL}^{-1}$ PAAc-SiNPs for 12 hours, f2) $100 \mu \mathrm{g} \cdot \mathrm{mL}^{-1}$ PAAc-SiNPs for 12 hours, f1) $50 \mu \mathrm{g} \cdot \mathrm{mL}^{-1}$ PAAc-SiNPs for $24 \mathrm{hours}$, f2) $100 \mu \mathrm{g} \cdot \mathrm{mL}^{-1}$ PAAc-SiNPs for 24 hours. In a1-g2), Red images taken with 40x objective showing fluorescence from SiNPs (Left panel); Blue images taken with 40x objective showing minimal DAPI staining (middle panel); The emerge (right panel). 


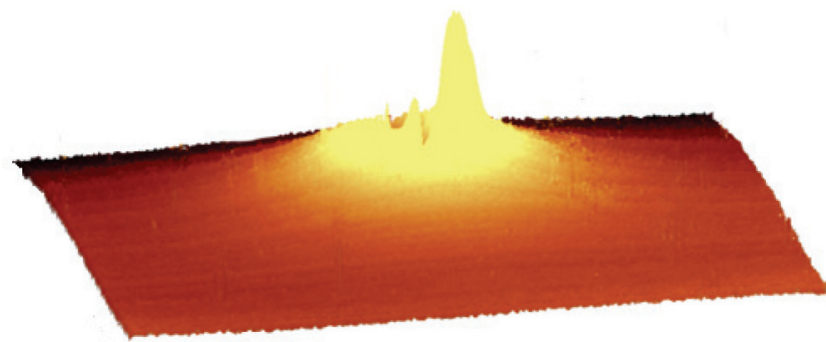

Figure 6. Reconstructed 3-D confocal z-stack image of HepC2 cells treated with $100 \mu \mathrm{g} \cdot \mathrm{mL}^{-1}$ PAAc-SiNPs for 24 hours (Images were collected at $0.37 \mu \mathrm{m}$ intervals with the $488 \mathrm{~nm}$ laser to create a stack in the $\mathrm{Z}$ axis).

nanoparticles. In general, cells can survive short-term exposure to low particle concentrations $(<10 \mu \mathrm{g} / \mathrm{mL})$ but at high doses, several groups have found cytotoxic effects begin to emerge for most nanoparticles in a dose- and time-dependent manner. ${ }^{[20,34-40]}$ Despite significant intracellular accumulation of PAAc-SiNPs in HHL5, HepG2, and 3T3-L1 cells, exposure to the SiNPs at $<200 \mu \mathrm{g} \cdot \mathrm{mL}^{-1}$ for up to 48 hours was not associated with any demonstrable cell toxicity (Figure 3 and 4). The generation of reactive oxygen species and the influence of cell uptake of nanoparticles are two common suggestions for raised cytotoxicity effects in cells. ${ }^{[41]}$ In addition, Hoshino et al. demonstrated that the degree of SiNP toxicity is independent of the nanocrystal itself but determined by the surface makeup. ${ }^{[2]}$ Compared with nanoparticles incorporating heavy metals, such as cadmium or lead, PAAc SiNPs contain no heavy metals and are capped by a covalently bonded poly-acrylic acid layer that is likely to render them less toxic. ${ }^{[43,44]}$ Furthermore, Goodman et al, have suggested that surface charge also plays a role in toxicity with cationic surfaces being more toxic than anionic, and being less biocompatible, which may be due to the affinity of cationic particles to the negatively charged cell membrane. ${ }^{[45]}$ The poly-acrylic acid coating used here is indeed an anionic carboxylated surface layer, which should be less toxic, but may reduce the uptake speed as it is likely to interact with the negatively charged cell membrane.

Results from some groups working on silica nanoparticles show low cytotoxicity of silica NPs. ${ }^{[46-49]}$ Lewinski et al. suggested that gold nanoparticles were applicable as a reference nanoparticle for low toxicity (15\% reduction in cell viability, at $\left.200 \mu \mathrm{g} \cdot \mathrm{mL}^{-1}\right) \cdot{ }^{[20]}$ In this case, PAAc-SiNP performsbetter than the reference as no significant difference of cell proliferation and viability was found between the control samples and those exposed to PAAc-SiNPs at $200 \mu \mathrm{g} \cdot \mathrm{mL}^{-1}$.

Although the interaction between nanoparticles and living cells remains to be understood fully, the nanoparticle internalization in most cells occurs primarily through active endocytic or phagocytic mechanisms. ${ }^{[48,50]} \mathrm{He}$ et al. suggested the degree and speed of cellular uptake was diverse owing to the range of different nanoparticle functional groups ${ }^{[51]}$ Because of the electrostatic binding between the positively charged capping layer and the negative cell membrane, under fixed conditions, the greater the positive charge of the particles (which depends on the outer layer functional group), the quicker the rate of uptake.
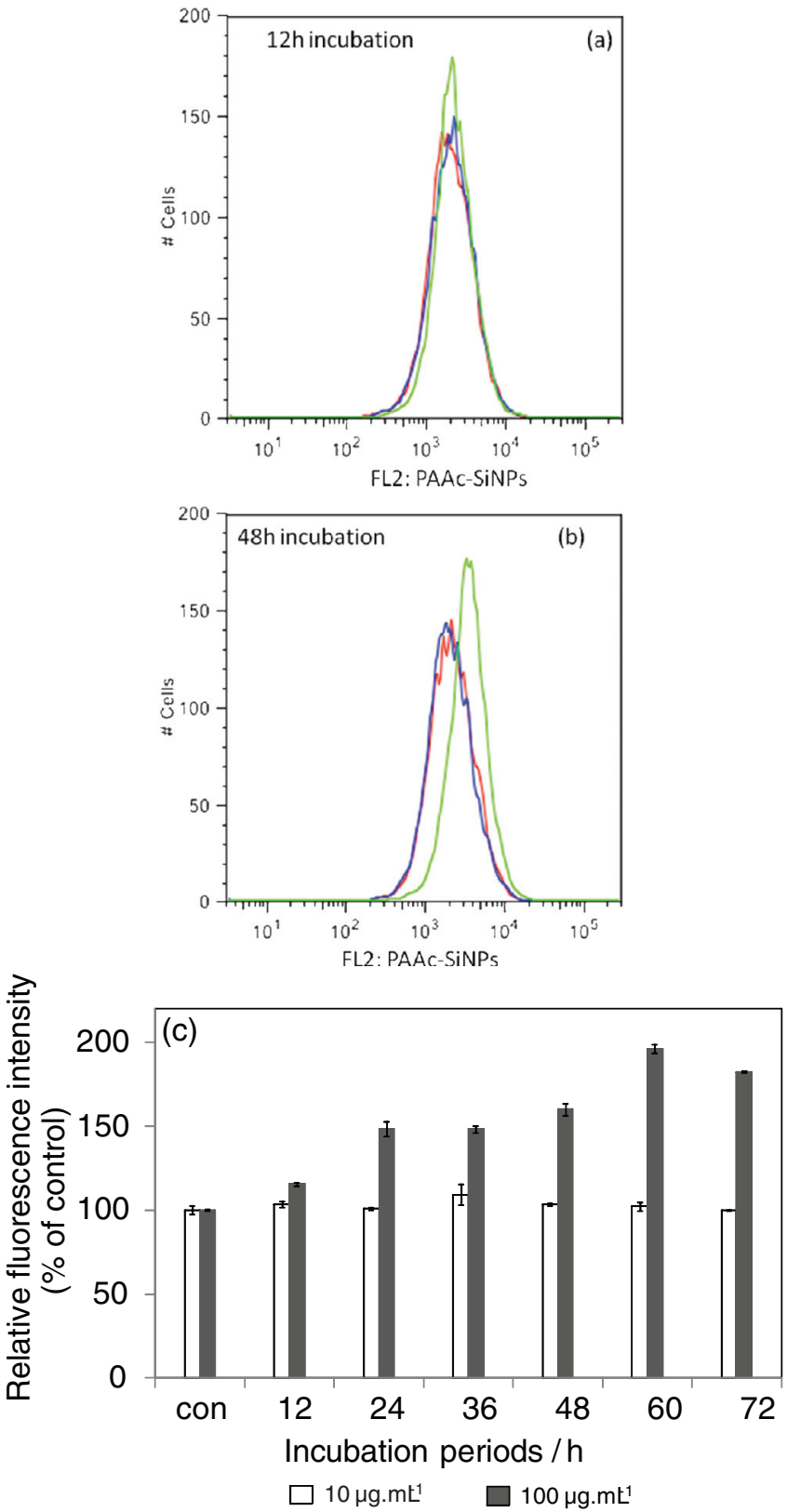

Figure 7. Uptake efficiency of SiNPs in HepG2 cells with various incubation times. HepG2 cells were exposed to PAAc-SiNPs for 12, 24, 36, 48,60 , and 72 hours at two concentrations of 10 or $100 \mu \mathrm{g} \cdot \mathrm{mL}^{-1}$. Red, control; blue, PAAc-SiNP $10 \mu \mathrm{g} \cdot \mathrm{mL}^{-1}$; green, PAAc-SiNP $100 \mu \mathrm{g} \cdot \mathrm{mL}^{-1}$. (a) 12 hours incubation; (b) 48 hours incubation; (c) collective results, which are presented as percentage of untreated control cells $10 \mu \mathrm{g} \cdot \mathrm{mL}^{-1}$ (white) or $100 \mu \mathrm{g} \cdot \mathrm{mL}^{-1}$ (dark). Values are mean $\pm \mathrm{SD}$ of the results from three independent experiments.

Small nanoparticles that facilitate delivery into the dense collagen matrix of a tumor can be used as a powerful drug delivery agent for antitumor treatment. ${ }^{[1,52]}$ However, the loading capacity per particle is limited, therefore a sufficient quantity of nanoparticles needs to be delivered into the target. Using both flow cytometry and fluorescence confocal microscopy, we have found 

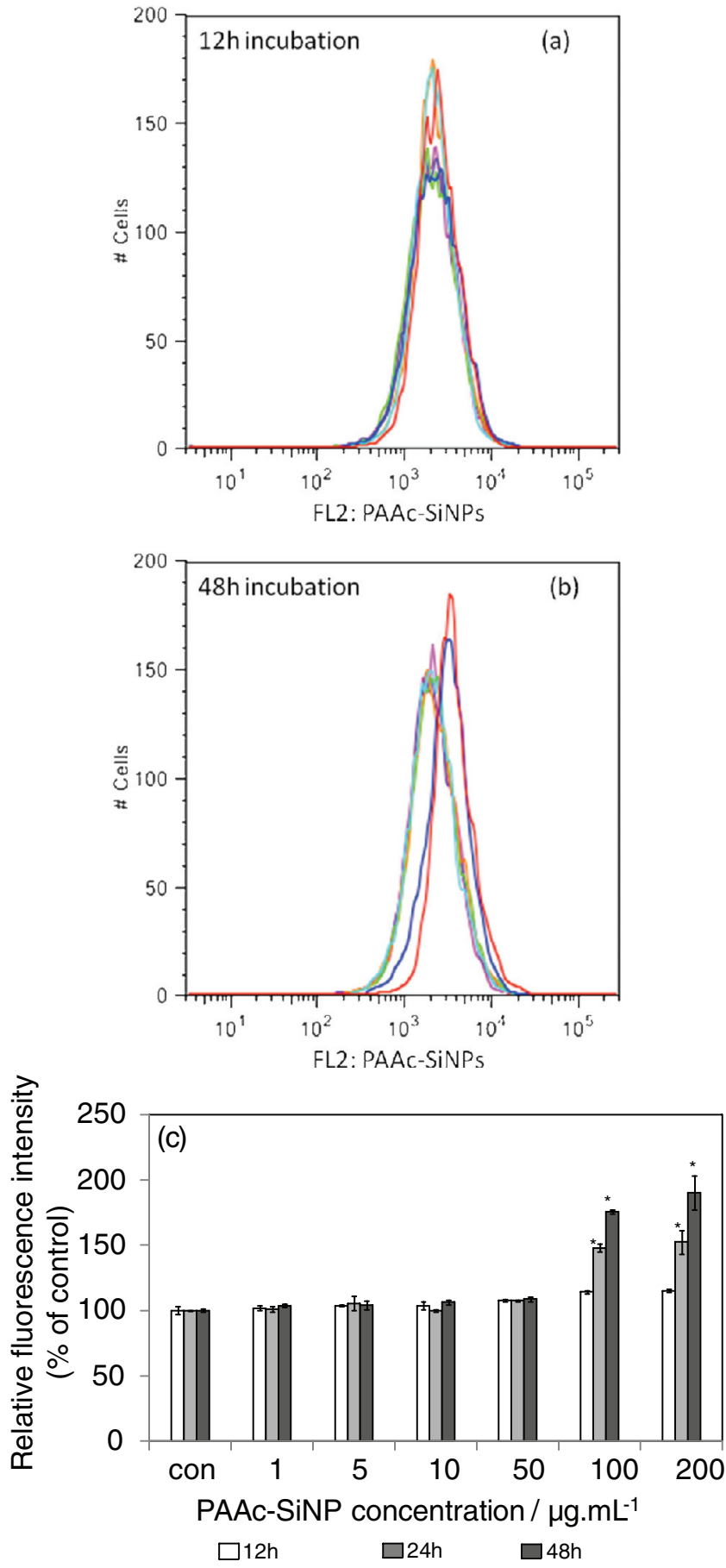

Figure 8. Uptake efficiency of SiNPs in HepG2 cell with variable concentrations. HepC2 cell were exposed to PAAc-SiNPs at concentration of $1,5,10,50,100$ and $200 \mu \mathrm{g} \cdot \mathrm{mL}^{-1}$. Pink, control; purple SiNP $1 \mu \mathrm{g} \cdot \mathrm{mL}^{-1}$; green, $\mu \mathrm{g} \cdot \mathrm{mL}^{-1}$; orange PAAc-SiNP $\mu \mathrm{g} \cdot \mathrm{mL}^{-1}$; light blue, PAAc-SiNP $\mu \mathrm{g} \cdot \mathrm{mL}^{-1}$; blue, PAAc-SiNP $100 \mu \mathrm{g} \cdot \mathrm{mL}^{-1}$; red, PAAc-SiNP $200 \mu \mathrm{g} \cdot \mathrm{mL}^{-1}$. (a) 12 hours incubation; (b) 48 hours incubation; (c) collective results, which are presented as a percentage of untreated control cells, 12 hours (white), 24 hours (light grey), and 48 hours (dark). Values are mean \pm SD of the results from three independent experiments. $* p<0.05$ versus control. that the cells can take up SiNPs when exposed to high concentrations $\left(>50 \mu \mathrm{g} \cdot \mathrm{mL}^{-1}\right)$. The uptake of PAAc-SiNPs in both human and mouse cells was found to show a time-dependent behaviour, which implies an activated mechanism involved in their uptake. PAAc-SiNPs were internalized within 2 hours, and the cellular accumulation increased with incubation time in the presence of nanoparticles in the medium. PAAc-SiNPs were found distributed within the cytosolic (Figure 5 and 6). The accumulation of PAAc-SiNPs was suggested to be due to endocytosis as well as internalization of membrane and cell cycle, as inhibitions of such processes were found to demonstrate a very significant suppression in the uptake rate and on the extent of intracellular accumulation in various cell types. ${ }^{[18]}$ During endocytosis of nanoparticles, the vesicles encapsulating the nanoparticles are called endosomes, which are then trafficked to various cellular compartments. ${ }^{[33]}$ Statistically significant fluorescence could only be detected with flow cytometry when the particle concentration was greater than $100 \mu \mathrm{g} \cdot \mathrm{mL}^{-1}$ and the incubation time longer than 24 hours. However, confocal microscopy can detect the concentration as low as $50 \mu \mathrm{g} \cdot \mathrm{mL}^{-1}$ and incubation time as less as 2 hours.

We measured cellular uptake of the particles semiquantitatively by flow cytometry. The instrument gave the accumulated intensity of the particles fluorescent in a number of cells (i.e. 5000 cells). So we can know the total fluorescent of particles in one cell, however, not the number of particles in one cell. A new paper just published by Prof Dawson's group took the same approach as ours. ${ }^{[54]}$ In the future, if the fluorescence from single NP could be detected, it would provide a route to calculate the exact number of nanoparticles inside the cells.

Further study is necessary to combine luminescence and signals from proteins or nucleic acids that interact with cognate ligands on SiNPs to determine spatiotemporal localization together with information about functional interaction. ${ }^{[18]}$ This technique would offer potential application in studying and even manipulating intracellular interactions that are of importance in various pathways involved in regulating a variety of cellular functions.

\section{Conclusions}

Poly-acrylic acid terminated silicon nanoparticles were employed as a synchronous fluorescent signal indicator. The effects of the silicon nanoparticles on the proliferation and viability of four cell lines have been investigated: HHL5, HepG2, 3T3-L1 pre-adipocyte and 3T3-L1 mature adipocyte. It was found that PAAc-SiNPs lack in vitro cellular toxicity and show quick accumulation in both human and mouse cells. Results from both confocal microscopy and flow cytometry suggest a time-dependent uptake of PAAc-SiNPs at higher concentrations. This uptake shows a widespread cellular distribution. These observations may offer potential for advanced biological imaging techniques and targeted drug delivery. 


\section{Experimental Section}

\subsection{Preparation of Poly-acrylic Acid Silicon Nanoparticles}

The preparation of the PAAc-SiNPs used here has been described previously. ${ }^{[25]}$ A brief summary of the procedure is provided. Photoluminescent porous silicon layers were formed by galvanostatic anodization of a boron-doped p-Si (100) chip (size approx. $1.25 \mathrm{~cm} \times 1.25 \mathrm{~cm}, 10 \Omega \cdot \mathrm{cm}$ resistivity, Compart Technology, Peterborough, UK) in a $1: 1 \mathrm{v} / \mathrm{v}$ solution of $48 \%$ aqueous hydrofluoric acid (HF) and ethanol solution. A layer of luminescent porous silicon was made at a relatively high current density $\left(5\right.$ minutes at $\left.560 \mathrm{~mA} \cdot \mathrm{cm}^{-2}\right)$. The reacted solution was decanted and the resulting hydrogen-terminated porous silicon chips were dried under vacuum. The chips were then introduced into a 1:9 (v: v) acrylic acid: ethanol aqueous solution. The mixture was kept under UV irradiation with magnetic stirring for 3-6 hours for the acrylic acid to react with the Si-H surface sites. The resulting solution was centrifuged and filtered to remove unreacted acid and large particles. Finally the dry sample was obtained by reduced pressure under vacuum. This is a facile approach to synthesize PAAc-SiNPs.

For the silicon nanoparticles described here, the initial hydrogen termination layer on the etched wafer serves a dual role: first as a convenient molecular anchor point at which surface modification may be performed, and second as an interim guard against oxidation in order to preserve the chemical character of the silicon core prior to subsequent functionalization steps.

\subsection{Nanoparticle Characterization}

The hydrodynamic diameter of the PAAc-SiNPs was determined by dynamic light scattering (DLS) with Zetasizer Nano ZS (Malvern Instruments Ltd). The scattered photons were detected under an angle of $173^{\circ}$, and the relative number distribution was obtained. The PAAc-SiNPs were dissolved in PBS. In order to obtain the diameter of SiNPs as closer as possible to real size, ultrasonication and filtration were applied before any measurement. XPS measurements were performed with a SCIENTA ESCA300 XPS analyser at the National Centre for Electron Spectroscopy and Surface Analysis (NCESS) at Daresbury Laboratory. A few drops of a suspension of the PAAC-SiNPs in DI water were cast onto gold film. The film was introduced immediately into a load-lock attached to ultra high vacuum (UHV) chamber in which the typical pressure was maintained below $5 \times 10^{-9}$ mbar. All spectra were acquired at normal emission with $\mathrm{Al} \mathrm{K} \alpha$ radiation at $1486.7 \mathrm{eV}$, with the energy resolution $\mathrm{E} /$ $\mathrm{dE}$ kept at $\sim 6 \times 10^{3}$. In all photoemission spectra, binding energies were referred to the Fermi edge measured on a gold foil in direct electrical contact with samples.

\subsection{Colorimetric MTT Assay}

To evaluate the cytotoxicity of PAAc-SiNPs, an MTT [3-(4,5-dimethylthiazol-2-yl)-2,5-diphenyltetrazolium bromide] assay was performed to determine cell viability. ${ }^{[35,55-58]}$ MTT measures mitochondrial activity using tetrazolium salts as mitochondrial dehydrogenase enzymes cleave the tetrazolium ring, which only occurs in living cells. ${ }^{[59]}$ Briefly, HHL-5, HepG2, 3T3-L1 cells were seeded in a 96-well plate for 24 hours. Then the cells were treated with PAAc-SiNPs at various concentrations $\left(0,0.1,1,10,50,100\right.$ and $\left.200 \mu \mathrm{g} \cdot \mathrm{mL}^{-1}\right)$ for various periods of time ( 24 and 48 hours). All experiments were repeated on at least three different occasions. After incubation for the specified times, the medium was removed followed by washing the cells with PBS. The medium was then changed and incubated with MTT solution (5 mg/mL) for 2 hours. The medium was removed, and formazan was solubilized in dimethylsulfoxide (DMSO). The absorbance was recorded on a microplate reader at the wavelength of $540 \mathrm{~nm}$. The percentage of viable cells was estimated by comparison with the untreated control cells.

For the MTT assay, HepG2 cells were seeded at $3 \times 10^{4}$ per well (96-well plate) one day in advance. The doubling time of the cell is 48 hours. After 24 and 48 hour treatment, the average absorbance value for control cell was 0.8552 and 1.1216 , respectively. This indicated cell number increased in culture media. Absorbance was read at $540 \mathrm{~nm}$, blanking on control wells.

3T3-L1 preadipocytes were incubated with Dulbecco's modified essential medium

(DMEM) supplemented with $10 \%$ calf serum (CS) at $37{ }^{\circ} \mathrm{C}$ in humidified atmosphere with $5 \% \mathrm{CO}_{2}$. To obtain mature adipocytes, pre-adipocytes were seeded $5 \times 10^{5}$ per well in a 6 well plate. After 24 hours, the cells were stimulated to differentiate in differentiation medium I (DMEM supplemented with $10 \%$ Fetal Bovine Serum (FBS) plus $0.1 \mu \mathrm{M}$ Dexamethasone, $0.5 \mathrm{mM}$ IBMX and insulin $5 \mu \mathrm{g} \cdot \mathrm{ml}^{-1}$ ) for 2 days. Cells were grown in differentiation medium II (DMEM supplemented with $10 \%$ Fetal Bovine Serum (FBS) plus insulin $5 \mu \mathrm{g} \cdot \mathrm{ml}^{-1}$ ) for another 2 days. Then cells were grown in DMEM supplemented with $10 \%$ FBS. Media were changed every 2 days. After 8-10 days, over $90 \%$ of the cells were able to differentiate. Mature adipocytes have lipid droplets, while preadipocytes do not.

\subsection{Trypan Blue Staining Assay}

The effect of PAAc-SiNPs on the viability of HepG2 cells was estimated by trypan blue staining assay. Trypan blue can stain dead cells, because it is only permeable to cells with compromised membranes. ${ }^{[60]}$ Briefly, HepG2 cells were treated with PAAc-SiNPs $(0 \sim 200 \mu \mathrm{g} / \mathrm{mL})$ for 24 and 48 hours. Then, $30 \mu \mathrm{L}$ of the cells was incubated for 5 minutes at room temperature with an equal volume of $0.4 \%(\mathrm{w} / \mathrm{v})$ trypan blue stain (Invitrogen). Cells were counted using a light microscope (TMS Nikon, Tokyo, Japan) and hemocytometer. Results were shown as the percentages of viable cells out of total cells counted.

\subsection{DNA Damage Assays}

DNA damage analyses, or alkaline comet assays, ${ }^{[33]}$ were performed to investigate DNA damage in response to PAAc-SiNPs. DNA lesions, including DNA single and double-strand breaks (SSBs, DSBs, respectively), as well as DNA base damage, 
were assessed in single cells treated with silicon nanoparticles using alkaline comet assays. HepG2 and HHL5 cell lines were investigated. Cells were exposed to $\mathrm{H}_{2} \mathrm{O}_{2}(50 \mu \mathrm{M})$ or SiNP $\left(1,10,100 \mu \mathrm{g} \cdot \mathrm{ml}^{-1}\right)$, or the vehicle alone, and harvested at 1 hour. Cell suspensions $\left(1.5 \times 10^{4}\right)$ were mixed with $0.6 \%$ low melting temperature agarose at $37{ }^{\circ} \mathrm{C}$ and immediately transferred onto a super frosted slide, which was pre-coated with $1 \%$ normal melting point agarose. After solidifying (15 minutes at $4{ }^{\circ} \mathrm{C}$ ), the slides were submerged in a pre-chilled lysis buffer (2.5 m NaCl, $100 \mathrm{~mm} \mathrm{Na}{ }_{2}$ EDTA pH 10, $10 \mathrm{~mm}$ Tris Base, and $1 \%$ Triton $\mathrm{X}-100)$ at $4{ }^{\circ} \mathrm{C}$ for 60 minutes and incubated in an alkaline unwinding solution $(300 \mathrm{~mm} \mathrm{NaOH}$, and $1 \mathrm{~mm}$ $\mathrm{Na}_{2}$ EDTA, pH13) for 30 minutes at $4{ }^{\circ} \mathrm{C}$. Damaged and undamaged nuclear DNA was then separated by electrophoresis for 30 minutes at $21 \mathrm{~V}$. The slides were washed in neutralisation buffer (0.4 M Tris-HCl, pH7.5) for 30 minutes, and stained with SYBR-green I. Comets were visualized using a fluorescence microscope, and images captured using a digital camera. Images were analyzed using Comet IV software and comet tail length was calculated as the distance between the end of nuclei heads and the end of each tail. Tail moments were defined as the product of the\%DNA in each tail. Each bar represented the average of 60 cells \pm S.E., and data are representative of experiments performed three times.

\subsection{Flow Cytometry}

HepG 2 cells were seeded on 12 -well plates at a density of $5 \times 10^{4}$ cells perwell and incubated at $37^{\circ} \mathrm{C}$ overnight. After treatment with $1,5,10,50,100$ or $200 \mu \mathrm{g} / \mathrm{mL}$ of SiNPs for $12-72 \mathrm{~h}$, cells were harvested by trypsinization. Then cells were centrifuged at $180 \times \mathrm{g}$ for 6 minutes at $4{ }^{\circ} \mathrm{C}$, pellet washed with cold PBS then suspended in $400 \mu \mathrm{l}$ cold PBS. Flow cytometry was performed with an Accuri C6 Flow Cytometer System using $488 \mathrm{~nm}$ excitation with 5,000 events from each sample, and analysis was performed using FlowJo software.

\subsection{Confocal Laser Scanning Microscopy}

The nanocrystals, being highly hydrophilic, were suspended in sterile distilled water to being introduced in culture medium. HepG2 and 3T3-L1 preadipocyte cells were selected to do confocal images. Cells was seeded on 12 -well plates with cover slips at a density of $5 \times 10^{4}$ cells per well and exposed to 50 or $100 \mu \mathrm{g} \cdot \mathrm{mL}^{-1}$ of SiNPs for 2-24 hours. The cells were then washed twice by PBS and fixed by ice-cold methanol. Cover slips with intact cells were inverted and mounted on a microscope slide using mounting gel. The images were taken under a confocal microscope (Zeiss LSM510 META system with an excitation wavelength $488 \mathrm{~nm}$ and emission between 550 and $650 \mathrm{~nm}$ ) using a 40× oil immersion objective lens. Z-series images were collected with stepper motor.

\subsection{Statistical Analysis}

All data are representative of at least three independent experiments. Data are presented as means \pm SD. Statistical significance was determined using a one-way analysis of variance between the two groups. The criterion for significance was set at $p<0.05$.

\section{Supporting Information}

Supporting Information is available from the Wiley Online Library or from the author.

\section{Acknowledgements}

QW is grateful to the International Scholarship Funding panel of the University of East Anglia for the award of an international scholarship. YC is grateful to the Royal Society for awarding a Research Grant 2007/ R2 and EPSRC for financial support under the project EP/G01664X/1. NCESS is acknowledged for awarding XPS beamtime. The authors are extremely grateful to Dr. Arvind Patel (MRC Virology Unit, Glasgow) for providing the immortalised human hepatocytes.

Received: October 22, 2011

Revised: January 16, 2012

Published online: February 16, 2012

[1] C. Wong, T. Stylianopoulos, J. Cui, J. Martin, V. P. Chauhan, W. Jiang, Z. Popović, R. K. Jain, M. G. Bawendi, D. Fukumura, Proc. Natl. Acad. Sci. 2011, 108, 2426.

[2] X. Michalet, F. F. Pinaud, L. A. Bentolila, J. M. Tsay, S. Doose, J. J. Li, G. Sundaresan, A. M. Wu, S. S. Gambhir, S. Weiss, Science 2005, 307, 538.

[3] Y. He, C. H. Fan, S. T. Lee, Nano Today 2010, 5, 282.

[4] R. D. Tilley, J. H. Warner, K. Yamamoto, I. Matsui, H. Fujimori, Chem. Commun. 2005, 1833.

[5] Y. Chao, L. Šiller, S. Krishnamurthy, P. R. Coxon, U. Bangert, M. Gass, L. Kjeldgaard, S. N. Patoleo, L. H. Lie, N. O'Farrell, T. A. Alsop, A. Houlton, B. R. Horrocks, Nat. Nano. 2007, 2, 486.

[6] H. Xu, R. Hong, T. X. Lu, O. Uzun, V. M. Rotello, J. Am. Chem. Soc. 2006, 128, 3162.

[7] H. Arya, Z. Kaul, R. Wadhwa, K. Taira, T. Hirano, S. C. Kaul, Biochem. Biophys. Res. Commun. 2005, 329, 1173.

[8] X. Gao, Y. Cui, R. M. Levenson, L. W. K. Chung, S. Nie, Nat Biotech 2004, 22, 969

[9] N. T. K. Thanh, L. A. W. Green, Nano Today 2010, 5, 213.

[10] F. Wang, W. B. Tan, Y. Zhang, X. P. Fan, M. Q. Wang, Nanotechnology 2006, 17, R1.

[11] T. Jamieson, R. Bakhshi, D. Petrova, R. Pocock, M. Imani, A. M. Seifalian, Biomaterials 2007, 28, 4717.

[12] S. Sato, M. T. Swihart, Chem. Mater. 2006, 18, 4083.

[13] D. S. English, L. E. Pell, Z. Yu, P. F. Barbara, B. A. Korgel, Nano Lett. 2002, 2, 681 .

[14] G. Belomoin, J. Therrien, A. Smith, S. Rao, R. Twesten, S. Chaieb M. H. Nayfeh, L. Wagner, L. Mitas, Appl. Phys. Lett. 2002, 80, 841.

[15] E. Rogozhina, G. Belomoin, A. Smith, L. Abuhassan, N. Barry, O. Akcakir, P. V. Braun, M. H. Nayfeh, Appl. Phys. Lett. 2001, 78, 3711.

[16] C. Delerue, G. Allan, M. Lannoo, Phys. Rev. B 1993, 48, 11024.

[17] I. Seotsanyana-Mokhosi, N. Kuznetsova, T. Nyokong, J. Photochem. Photobiol. A. 2001, 140, 215.

[18] N. H. Alsharif, C. E. M. Berger, S. S. Varanasi, Y. Chao, B. R. Horrocks, H. K. Datta, Small 2009, 5, 221.

[19] L. Ruizendaal, S. Bhattacharjee, K. Pournazari, M. Rosso-Vasic, L. H. J. de Haan, G. M. Alink, A. T. M. Marcelis, H. Zuilhof, Nanotoxicology 2009, 3, 339. 
[20] N. Lewinski, V. Colvin, R. Drezek, Small 2008, 4, 26.

[21] M. Green, E. Howman, Chem. Commun. 2005, 121.

[22] A. M. Derfus, W. C. W. Chan, S. N. Bhatia, Nano Lett. 2003, 4, 11.

[23] K. Fujioka, M. Hiruoka, K. Sato, N. Manabe, R. Miyasaka, S. Hanada, A. Hoshino, R. D. Tilley, Y. Manome, K. Hirakuri, K. Yamamoto, Nanotechnology 2008, 19, 415102.

[24] Y. Chao, Q. Wang, A. Pietzsch, F. Hennies, H. Ni, Phys. Status Solidi A 2011, 208, 2424

[25] Q. Wang, H. Ni, A. Pietzsch, F. Hennies, Y. Bao, Y. Chao, J. Nanopart. Res. 2011, 13, 405.

[26] L. K. Limbach, R. Bereiter, E. Mueller, R. Krebs, R. Gaelli, W. J. Stark, Environ. Sci. Technol. 2008, 42, 5828.

[27] W. J. Stark, Angew. Chem. Int. Ed. 2011, 50, 1242.

[28] P. R. Coxon, Q. Wang, Y. Chao, J. Phys. D: Appl. Phys. 2011, 44, 495301.

[29] A. B. Sieval, B. van den Hout, H. Zuilhof, E. J. R. Sudholter, Langmuir 2001, 17, 2172.

[30] X. Wallart, C. H. de Villeneuve, P. Allongue, J. Am. Chem. Soc. 2005, $127,7871$.

[31] L. Šiller, S. Krishnamurthy, L. Kjeldgaard, B. R. Horrocks, Y. Chao, A. Houlton, A. K. Chakraborty, M. R. C. Hunt, J. Phys.-Condes. Matter 2009, 21, 095005.

[32] F. M. Dickinson, T. A. Alsop, N. Al-Sharif, C. E. M. Berger, H. K. Datta, L. Siller, Y. Chao, E. M. Tuite, A. Houlton, B. R. Horrocks, Analyst 2008, 133, 1573.

[33] G. U. Dachs, A. V. Patterson, J. D. Firth, P. J. Ratcliffe, K. M. S. Townsend, I. J. Stratford, A. L. Harris, Nature Medicine 1997, 3, 515

[34] S. T. Selvan, T. T. Tan, J. Y. Ying, Adv. Mater. 2005, 17, 1620.

[35] C. M. Sayes, J. D. Fortner, W. Guo, D. Lyon, A. M. Boyd, K. D. Ausman, Y. J. Tao, B. Sitharaman, L. J. Wilson, J. B. Hughes, J. L. West, V. L. Colvin, Nano Lett. 2004, 4, 1881.

[36] D. X. Cui, F. R. Tian, C. S. Ozkan, M. Wang, H. J. Gao, Toxicol. Lett. 2005, 155, 73

[37] S. K. Manna, S. Sarkar, J. Barr, K. Wise, E. V. Barrera, O. Jejelowo, A. C. Rice-Ficht, G. T. Ramesh, Nano Lett. 2005, 5, 1676.

[38] F. X. Hu, K. G. Neoh, L. Cen, E. T. Kang, Biomacromolecules 2006, 7, 809.
www.MaterialsViews.com

[39] J. P. Ryman-Rasmussen, J. E. Riviere, N. A. Monteiro-Riviere, J. Invest. Dermatol. 2007, 127, 143.

[40] Y. F. Liu, W. Chen, A. G. Joly, Y. Q. Wang, C. Pope, Y. B. Zhang, J. O. Bovin, P. Sherwood, J. Phys. Chem. B 2006, 110, 16992.

[41] E. Chang, N. Thekkek, W. W. Yu, V. L. Colvin, R. Drezek, Small 2006, 2, 1412.

[42] A. Hoshino, K. Fujioka, T. Oku, M. Suga, Y. F. Sasaki, T. Ohta, M. Yasuhara, K. Suzuki, K. Yamamoto, Nano Letters 2004, 4, 2163.

[43] L. Wang, D. K. Nagesha, S. Selvarasah, M. R. Dokmeci, R. L. Carrier, J. Nanobiotech. 2008, 6, 11.

[44] R. Hardman, Environ. Health Perspect. 2006, 114, 165.

[45] C. M. Goodman, C. D. McCusker, T. Yilmaz, V. M. Rotello, Bioconjugate Chemistry 2004, 15, 897.

[46] T. J. Brunner, P. Wick, P. Manser, P. Spohn, R. N. Grass, L. K. Limbach, A. Bruinink, W. J. Stark, Environ. Sci. Technol. 2006, 40, 4374

[47] A. T. Bauer, E. A. Strozyk, C. Gorzelanny, C. Westerhausen, A. Desch, M. F. Schneider, S. W. Schneider, Biomater. 2011, 32, 8385.

[48] L. Hu, Z. Mao, Y. Zhang, C. Gao, J. Nano. Lett. 2011, 1, 1.

[49] J. L. Vivero-Escoto, I. I. Slowing, V. S. Y. Lin, Biomater. 2010, 31, 1325.

[50] K. Thurn, E. Brown, A. Wu, S. Vogt, B. Lai, J. Maser, T. Paunesku, G. Woloschak, Nanoscale Research Letters 2007, 2, 430

[51] X. He, F. Liu, K. Wang, J. Ge, D. Qin, P. Gong, W. Tan, Chin. Sci. Bull. 2006, 51, 1939.

[52] V. H. B. Ho, N. K. H. Slater, R. J. Chen, Biomaterials 2011, 32, 2953.

[53] S. Ferrati, A. Mack, C. Chiappini, X. W. Liu, A. J. Bean, M. Ferrari, R. E. Serda, Nanoscale 2010, 2, 1512.

[54] T. dos Santos, J. Varela, I. Lynch, A. Salvati, K. A. Dawson, Small 2011.

[55] N. A. Monteiro-Riviere, A. O. Inman, Carbon 2006, 44, 1070.

[56] R. Shukla, V. Bansal, M. Chaudhary, A. Basu, R. R. Bhonde, M. Sastry, Langmuir 2005, 21, 10644.

[57] E. E. Connor, J. Mwamuka, A. Gole, C. J. Murphy, M. D. Wyatt, Small 2005, 1, 325

[58] A. Magrez, S. Kasas, V. Salicio, N. Pasquier, J. W. Seo, M. Celio, S. Catsicas, B. Schwaller, L. Forro, Nano Lett. 2006, 6, 1121.

[59] T. Mosmann, J. Immunol. Methods 1983, 65, 55.

[60] S. A. Altman, L. Randers, G. Rao, Biotechnol. Prog. 1993, 9, 671. 